\title{
ASPECTOS POLITIICOS E LINGUÍSTICOS NO ENSINO DE PORTUGUÊS PARA SURDOS
}

ROBERVAL TEIXEIRA E SILVA

\section{PREÂMBULO}

Este texto remete-se aos meus primeiros passos no estudo das relações entre língua e sociedade que, guiados pela professora Silvia Figueiredo Brandão, levaram-me a três caminhos:

- Descobrir-me como professor;

- Descobrir-me como sociolinguista;

- Descobrir-me como um professor-sociolinguista com profunda sensibilidade em relação ao espaço social que me cerca.

Estes três pontos são gerados e potencializados no momento em que, na Iniciação Científica, a professora Silvia me lançou nas mãos, em francês, o livro Langage et classes sociales: codes socio-linguistiques et contrôle social, de Basil Bernstein. Foi com este gesto que, dentro da universidade, meus olhos foram escancarados para olhar o mundo e a mim mesmo... As escolhas seguintes que fui fazendo, olhando de agora, estão, em muito, fundadas nessa atitude generosa em que as suas mãos pequeninas e firmes me conduziram a estudos sociolinguísticos preocupados com comunidades altamente desconfortáveis socialmente... como é o caso dos surdos, tema do artigo que aqui apresento. 


\section{INTRODUÇÃO}

Uma das maiores preocupações na educação do surdo assenta-se no processo de ensino-aprendizagem da Língua Portuguesa. Afinal, uma parte significativa de sua vida acadêmica, civil e pessoal sofre grande impacto em consequência do domínio ou não dessa língua. Até pouco tempo, o ensino do Português ao surdo se encaminhava da mesma forma como se encaminha ao ouvinte. Dentre outros fatores, este é um dos que mais contribuem para o insucesso que marca, em geral, na comunidade surda, esse processo. Por conta deste quadro de insucesso, criou-se, e ainda se cria, um imaginário poderoso que delineia o surdo como cognitivamente comprometido em relação às ditas "pessoas normais", os ouvintes. Entretanto, quando o ensino de Português para o surdo passa a ser visto sob outro ponto de vista, em termos pedagógicos, culturais e sociolinguísticos, a situação muda radicalmente de perfil.

Por exemplo: comparar crianças surdas e ouvintes em termos de competência no Português é como fazer o mesmo em relação às mesmas no que se refere à competência na LIBRAS (língua de sinais brasileira). Ouvintes e surdos constituem-se espontaneamente em línguas primeiras diferentes. Entretanto, como coloca Kristina Svartholm (1998), se ouvintes e surdos são comparados frente à aquisição de línguas segundas/estrangeiras, as diferenças em termos de competência tendem a ser redimensionadas:

(...) vários daqueles erros gramaticais, que foram descritos como peculiares aos surdos, estão bem longe de serem peculiares. (SVARTHOLM, 1998, p. 39)

Assim, a perspectiva a ser adotada é encarar o Português para o surdo como uma segunda língua; nesse sentido, o ensino-aprendizagem precisa de ser veiculado com base em outras perspectivas metodológicas também.

De maneira geral, há muita teorização em torno do ensino do Português para o surdo e muitas constatações de suas dificuldades em aprender uma língua oralizada. Temos, por exemplo, tido acesso a importantes trabalhos que apontam essas dificuldades (FERNANDES, 1990) e que, por isso, são fundamentais para nos indicar muitas questões cruciais e particulares ao surdo. Entretanto, o fato é que todos apontam o problema, mas ainda não foi possível encontrar caminhos efetivos que nos mostrem o que fazer para resolvê-lo. Existem poucas práticas de ensino de Português como língua não materna bem norteadas, e poucas experimentações com base em princípios claros. O resultado é que a grande maioria dos surdos acaba não alcançando um nível mínimo de proficiência em línguas orais de forma a ser capaz de interagir de forma eficiente. 
Para o surdo, como para qualquer minoria, o resultado do não acesso à língua da maioria constitui um fator extremamente sério social, cultural e politicamente. A situação política em que se encontra a comunidade surda oprime a mesma em uma posição de alijamento dentro da comunidade linguística hegemônica. Nesse sentido, sua existência enquanto grupo social e cultural acaba carregando a marca da marginalidade e de seus reflexos.

\section{DEFICIÊNCIA E DIFERENÇA}

Pensar a surdez sob a égide da deficiência pressupõe abordá-la no sentido da necessidade de um conserto. Nessa perspectiva, significa levar os surdos, imperativamente, a serem submetidos à imposição de aparelhos auditivos ou a processos de oralização para assemelhá-lo a um padrão - não deficiente - que é o ouvinte, por exemplo. Isso significa dizer desconsiderá-los enquanto comunidade linguística e culturalmente delimitada.

Em contato com opiniões gerais dos professores, obtidas através de conversas informais, entrevistas de projetos (TEIXEIRA E SILVA, 2004), encontros acadêmicos, podemos constatar uma percepção generalizada de que o surdo chega à sala de aula com uma série de "deficiências”. Esta postura tem relação com o que, em pesquisas em educação e em Linguística, já se chamou de "déficit linguístico" (BERNSTEIN, 1975) e de "déficit cultural” (MAGDA SOARES, 1986).

Bernstein fazia a distinção de duas categorias de códigos: o código restrito e o código elaborado ${ }^{1}$. Crianças usuárias do chamado código restrito, em geral de classe popular, costumavam ter um rendimento escolar mais baixo e a elas eram associadas incapacidades cognitivas; as que dominavam o designado código elaborado, em geral de classe média, tinham mais sucesso na escola e, portanto, eram consideradas mais capazes. Essa era uma visão problemática porque situava a relação entre língua e sociedade a um certo determinismo cultural e cognitivo imposto pela língua usada por cada grupo. Dessa discussão, surgiu a ideia de haver sujeitos menos e mais capazes na escola. A consequência disso é o tratamento

1 A designação "restrito" e "elaborado" é infeliz sob o ponto de vista da Sociolinguística interacional uma vez que marca uma variedade linguística como superior a outra. Apesar da designação, entretanto, as reflexões sobre essas diferenças são fundamentais para entender que se falam diferentes variedades de língua em função das experiências socioculturais que temos em nosso processo de socialização. Bernstein retorna aos dois conceitos mais tarde para indicar que não há hierarquização entre eles; o que ocorre é que a escola privilegia um deles (o elaborado) e isso faz com que os usuários do outro (o restrito) tenham significativas desvantagens, concretizadas em fracasso escolar, por exemplo. 
diferenciado que esses sujeitos recebiam e recebem hoje nas salas de aula em todas as partes do globo. Entretanto, uma recontextualização desses dois conceitos aponta para o fato de que o que está em jogo é a relação entre poder e controle dos sujeitos que usam o código elaborado sobre os que usam o código restrito; é uma relação política de opressão. O fundamental aqui é sublinhar que muitos educadores ainda pautam as suas práticas pedagógicas a partir dessa crença. Nesta visão, podem ser também inseridos os surdos, oprimidos por um processo de opressão entre línguas hegemônicas, como o Português, e línguas minoritárias como a LIBRAS.

Magda Soares (1986, p. 14) critica este tipo de posição, esclarecendo que "os termos deficiência, privação, carência remetem ao sentido de falha, falta, ausência; as expressões deficiência cultural, privação cultural, carência cultural significam, pois, basicamente, falta ou ausência de cultura". E isto não existe. Pessoas saudáveis não têm déficit cultural ou linguístico. Elas têm, sim, diferentes culturas e diferentes línguas.

Este mito da deficiência leva o professor a adotar um tratamento injustificadamente diferenciado com alunos de culturas diferentes e que necessariamente falam línguas diferentes. Em geral, isto significa dizer que se aposta menos em certos alunos e se aposta mais em outros. A resposta dos alunos é óbvia: vão ser mais ou menos estimulados a aprender seja lá a disciplina que for.

Parece haver uma ideia de que o aluno surdo não tem aptidão para a aprendizagem de uma outra língua, de uma língua segunda ou estrangeira. Como coloca Moita Lopes (1996, p. 75),

Embora a nossa sala de aula evidencie que os alunos fazem progressos diferentes na aprendizagem de LEs, os fatores que a influenciam são muitos (motivação, atitude, oportunidade, etc.) e não simplesmente a chamada aptidão para aprender línguas estrangeiras.

A questão que se coloca é que não se considera, nesse contexto, a língua dos surdos - a língua de sinais; e se a língua não é considerada, desconsidera-se uma identidade, uma cultura. É altamente pernicioso, então, tratar o surdo como deficiente. O que argumentamos, junto com outros teóricos, é que ele seja considerado no âmbito da diferença: língua diferente, cultura diferente, identidades diferentes. Só assim será possível pensar no surdo como cidadão.

Nesse sentido, um trabalho que pretenda pensar a surdez precisa de alicerçar-se a partir de uma discussão política.

- Onde se localiza socialmente a comunidade surda?

- Que espaços políticos são ocupados por eles? 
- De que forma se relacionam com o mundo dos ouvintes?

- Que representações os surdos têm de si mesmos, dos ouvintes e estes daqueles?

- Que valores simbólicos as línguas e culturas de surdos e de ouvintes são performatizados no espaço sociocultural em que convivem?

\section{DO ORALISMO AO BILIGUISMO}

No processo histórico de pensar o ensino de uma língua oralizada ao surdo, destacaremos três grandes abordagens: o oralismo, a comunicação total e, mais contemporaneamente, o bilinguismo.

Vamos, então, compreender a constituição de cada uma dessas perspectivas com alguns dos seus princípios, metodologias e suas implicações políticas e sociolinguísticas.

\subsection{O oralismo}

Na medida em que a surdez tradicionalmente é considerada uma deficiência, o seu tratamento em termos de educação foi a busca do reparo. O padrão para esse reparo eram os ouvintes/falantes de uma língua oralizada. Nesse sentido, desenvolve-se uma metodologia voltada para o "treinamento" dos surdos na língua oral: o oralismo.

Em conceito, essa visão pode ser assim definida (SOUZA, 1998, p. 4):

O "deficiente auditivo" sofre uma patologia crônica, traduzida por lesão no canal auditivo e/ou em área cortical que obstaculizando a "aquisição normal" da linguagem, demanda intervenções clínicas de especialistas, tidos como responsáveis quase únicos por "restituir a fala" a "esse tipo de enfermo".

Como se pode ver, o surdo é tratado como um doente que precisa de ser clinicamente tratado e, além disso, é considerada como normal apenas a aquisição de uma língua oralizada.

As bases dessa abordagem se fundamentam no fato de que a LIBRAS tem seu status inferior em relação à língua da comunidade de ouvintes. A fala é o seu grande objetivo. Também dela emerge a postura de encarar a surdez do ponto de vista meramente médico. Isso terá implicações sérias no sentido de se consolidar e considerar identidades e culturas surdas.

A medicalização e a normalização dos surdos referem um projeto hegemônico em que o ser falante/ouvinte constitui a especificidade de uma identidade totalitária, positiva e produtora, por sua vez, de uma norma invisível que a tudo ordena e regula. (SKLIAR, 1999, p. 12) 
Nesse sentido, o surdo era apenas um doente que precisava de tratamento. Tais tratamentos envolviam o implante e uso de aparelhos auditivos e "os árduos anos de treinamento auditivo, de leitura labial, de estimulação dos órgãos fonoarticulatórios, etc.” (SOUZA, 1998, p. 5). Ficava, assim, ignorada a posição de produtores de uma outra cultura, constituída em uma outra língua.

Aqui se instala mais puramente o discurso da deficiência, aquele que coloca o surdo como um ser humano de segunda categoria, cognitivamente comprometido em relação aos hegemônicos ouvintes. "O oralismo defende essencialmente a supremacia da voz, transformando-a em nuclear do que consideram ser o tratamento educativo interdisciplinar" (SOUZA, 1998, p. 4). Entretanto, como coloca Fernandes (1999, p. 95),

O som pode ser dispensado no processo de letramento, uma vez que sua ausência não impede o desenvolvimento da criança, no que se refere às diretrizes do domínio da língua.

Os resultados práticos do ponto de vista da oralização apontam para duas direções: a primeira é o fato de que nem todos os surdos têm habilidades, e mesmo acesso a canais de instrumentalização, que facilitem o processo de oralização; por outro lado, como já indica a primeira questão, a grande maioria dos surdos submetidos ao oralismo ficava de fora do processo educacional, que era pensado unicamente possível em uma língua oral, no nossa caso em Português; para entrar num processo de escolarização, o surdo deveria primeiramente aprender a ler lábios e a falar.

Não se defende aqui a não oralização do surdo. Acreditamos que essa não é a forma política e sociolinguística mais adequada para encaminhar a questão do ensino. Afinal, o tipo de postura que assume o oralismo é o da imposição política e social da comunidade linguística majoritária onde se encontra a comunidade surda. Acreditamos, também, que a oralização é um processo que deve ocorrer fora do espaço pedagógico, já que neste se pretende fornecer subsídios para o desenvolvimento de capacidades e habilidades científicas, intelectuais, políticas, sociais. Não nos parece que o duro processo de oralização vá ao encontro dos últimos objetivos apontados por nós. Ser capaz de falar e de ler lábios não podem ser tomados como pontos pré-requisitos para o desenvolvimento que o espaço pedagógico busca. Entretanto, se é dominado pela pessoa surda, não constitui um problema. Mas é preciso ficar claro em que espaço esse tipo de treinamento pode e deve se dar. Parece inapropriado que o cidadão surdo tenha de esperar por uma oralização, que pode nunca chegar a resultados satisfatórios, para ter acesso ao direito à escola.

O problema político-social mais grave dessa visão oralizadora é o fato de que, ao se negar uma língua natural a alguém, está se negando a socialização e o 
necessário processo de apropriação do mundo que se dá nas linguagens e, mais especificamente, nas línguas.

Emmanuelle Laborit (1994, p. 22), uma surda francesa, conta como se sentiu até os sete anos, idade até quando foi submetida a um processo de oralização e o momento em que entrou em contato com a língua francesa de sinais:

Aprendi essa linguagem (a de sinais) só aos sete anos. Antes era seguramente um pouco como uma "débil", uma selvagem. Era loucura. Como tudo acontecia antes? Não tinha língua. Como pude me construir? Como compreendia as coisas? Como fazia para chamar as pessoas?

São questões cruciais como estas que precisam de ser pensadas e que são geradas quando o surdo é submetido a metodologias advindas desse tipo de oralismo.

Em resumo, mesmo submetidos a esse conserto oralista, a comunicação com ouvintes ao fim das contas continuava muito insatisfatória e o fracasso escolar também se mantinha. Além disso, as atividades massacrantes e pouco produtivas do oralismo construíram nos surdos um verdadeiro pavor das línguas orais, no nosso caso, da Língua Portuguesa. Essa foi também uma experiência nossa no $\mathrm{CEPV}^{2}$, onde trabalhamos por vários anos. Para iniciar o trabalho de ensino de Português com segunda língua, foi necessário que antes fizéssemos um trabalho de sensibilização para que os alunos surdos desconstruíssem, paulatinamente, o bloqueio frente à língua oralizada com que iam entrar em contato mais metódico e se sentissem motivados a lidar com ela. Sem esse passo fundamental, nada poderia ter sido desenvolvido. Entretanto, essa desconstrução não pode se realizar efetivamente apenas na escola: há uma série de sujeitos e entidades que precisam de ser, digamos, reeducadas para haver essa desconstrução, como a área médica, os responsáveis, os cidadãos em geral, a Educação, a própria Linguística, e todos os profissionais envolvidos com a pessoa surda.

\subsection{A comunicação total}

Por conta dos problemas comunicativos entre professores e alunos surdos e do não desenvolvimento de uma maior habilidade interacional com ouvintes, começou-se a aceitar em sala de aula o uso de alguns sinais. Passou-se a trabalhar com um Português sinalizado; ou seja, fazia-se uma tentativa de usar a estrutura gramatical da Língua Portuguesa representada por sinais. Era um processo de pidginização no qual, em resumo, não se falava Português nem LIBRAS.

2 Centro Educacional Pilar Velazquez, escola bilíngue para surdos fechada em 2015. 
Mas a LIBRAS começava a ganhar espaço na escola, começava, ainda que incipientemente, a ser reconhecida como uma língua. Como se pode prever, este não foi um espaço ocupado sem polêmica; tanto nessa época quanto ainda hoje, alguns profissionais sociolinguisticamente fundamentados entendem que a LIBRAS e o Português ocupam espaços políticos e socioculturais diferentes, e essa polêmica não se coloca.

De qualquer forma, a ideia de se utilizar sinais, Português e, também, qualquer outro recurso comunicativo passou a ser considerada entre os profissionais ligados à educação de surdos. É esse contexto que ilustra uma outra abordagem, a da comunicação total (SOUZA, 1998: 8).

é uma filosofia que, na prática pedagógica, se traduz por uma "completa liberdade (...) de quaisquer estratégias, que permitem o resgate de comunicações, total ou parcialmente bloqueadas” (Ciccone, 1980, p. 7, grifo meu). "O objetivo é fornecer à criança a possibilidade de desenvolver uma comunicação real com seus pais e professores... A oralização não é o objetivo em si... mas uma das áreas trabalhadas para possibilitar a integração social do indivíduo surdo" (MOURA, 1993, p. 1, grifo meu).

Em resumo, na comunicação total tudo era permitido, o que quer dizer que na sala de aula o professor poderia lançar mão de qualquer processo comunicativo. A LIBRAS e o Português nesse contexto parecem já não manter a relação dessimétrica que encontrávamos no oralismo.

A problemática que surge dessa visão é o fato de que o processo interacional, para o ensino de uma língua, não se dava em uma mesma linguagem, pois "professores e alunos não falavam, via de regra, a mesma língua, isto é, não havia um sistema linguístico comum a ser compartilhado" (SOUZA, 1998, p. 10). Obviamente, nas nossas interações, sobretudo mais contemporaneamente em tempos de mobilidades de todos os tipos (TEIXEIRA E SILVA, 2012, 2015; BODOMO; TEIXEIRA E SILVA, 2012), lançamos mão de muitas linguagens e de muitas línguas; a língua não é responsável isolada, especial ou unicamente. Entretanto, no processo de interação para o ensino de uma língua em especial, é preciso planejar como diferentes sistemas semióticos podem colaborar.

O resultado desse processo junto ao aluno era a ausência de um parâmetro para o ensino de língua que fosse claro o suficiente no sentido de embasar um trabalho pedagógico. Afinal, uma aula de comunicação em que se trabalha com vários códigos ao mesmo tempo, visando à aprendizagem de um código em particular, não parece ser a melhor estratégia - sobretudo porque cada linguagem (língua, quadrinhos, dramatização...) tem suas próprias organizações discursivas. É preciso localizar cada linguagem em sua própria gênese. 
Assim, o caos instalado com a comunicação total punha em choque objeto e objetivos pedagógicos. Nesse sentido, essa abordagem parece tender ao fracasso, compreendida como foi colocada aqui em nosso trabalho.

Se estamos lidando com a ideia de que língua, cultura e sociedade estão inter-relacionadas, é metodologicamente impossível o ensino do Português através da filosofia da comunicação total. Afinal, nesta filosofia, não se considera a Língua Portuguesa e a LIBRAS como códigos diferentes e genuínos.

Em outras palavras, a necessidade de uma metodologia mais coerente com um trabalho pedagógico consciente, voltado para o ensino de línguas oralizadas, se apresentava aos profissionais da surdez.

\subsection{Um tipo de bilinguismo}

Mudando significativamente, então, esse contexto de educação e surdez, começa a se desenvolver uma forma diferente de encarar a pessoa surda. Se, antes, a palavra deficiência era a que mais fundamentalmente embasava as abordagens, agora se passa a um outro paradigma.

A virada linguística, os descentramentos do sujeito moderno, os novos olhares sobre as identidades, etc, parecem confluir a uma afirmação significativa: a surdez não é uma questão de deficiência, mas uma questão epistemológica, quer dizer, a relação entre o conhecer/saber e o poder se coloca em primeiro lugar (SKLIAR, 1998, p. xiii).

O ponto de vista, então, passa a ser, marcadamente, explicitamente, outro. Agora, passa-se veementemente a considerar a língua de sinais como um símbolo genuíno de um grupo cultural e, por isso, deslocamos o lugar do surdo no discurso pedagógico: em vez de serem lidos a partir de um discurso clínico, passam a ser narrados dentro de meandros político-sociais. Já não é mais a deficiência a questão, mas a diferença.

É a partir dessa visão que começa a se delinear uma terceira abordagem, rigorosamente opositiva a outros paradigmas: o bilinguismo.

É uma proposta de ensino usado por escolas que se propõem a tornar acessível à criança duas línguas no contexto escolar. Os estudos têm apontado para essa proposta como sendo a mais adequada para o ensino de crianças surdas, tendo em vista que considera a língua de sinais como língua natural e parte desse pressuposto para o ensino da língua escrita. (QUADROS, 1997, p. 27)

Ao discutir as outras duas abordagens de educação de surdos, temos colocado a problemática do respeito à língua, à identidade e à cultura surdas. Nesse 
sentido, a definição anteriormente sinaliza mas parece ainda não tocar em aspectos primordiais: estamos lidando aqui com um conflito ideológico, político, social e cultural entre uma minoria e uma maioria linguística. Nesse sentido, a adoção de dois idiomas veiculares na escola não pode ser um processo que focaliza a transmissão de informações, porque não se trata simplesmente de se ter direito a usar a própria língua para aprender uma outra. Línguas constituem, traduzem, transformam culturas. Assim, diferentes línguas deveriam trazer para o cenário da aula uma discussão socioculturalmente sensível. Uma das grandes problemáticas no ensino de minorias linguísticas, como os indígenas, por exemplo, ilumina-se a partir da discussão dessas questões: que lugares, na escola, ocupam a língua indígena dos alunos e a Língua Portuguesa? O Português é colocado como objeto superior? Os meninos e adultos precisam de aprender o Português para terem acesso a um letramento? Argumentamos que, se a LIBRAS é a língua dos surdos, é preciso garantir-lhes o direito de serem instruídos, letrados também nela.

(...) é um axioma afirmar que a língua materna - língua natural - constitui a forma ideal para ensinar uma criança (...). Obrigar um grupo a utilizar uma língua diferente da sua, mais do que assegurar a unidade nacional, contribui para que esse grupo, vítima de uma proibição, segregue-se cada vez mais da vida nacional (...) (Unesco, 1954)

Negar a língua de um grupo é negar-lhes a identidade. Como coloca Kleiman (1998, p. 268),

a perda de identidade desses grupos (minorias linguísticas) está geralmente simbolizada pela perda da língua materna, com consequência de um processo de deslocamento linguístico na direção da língua dominante (KLEIMAN, 1998, p. 268)

É, então, nesse âmbito que se vai situar o ensino bilíngue para surdos: assentado em pilares políticos e sociais.

A proposta de educação bilíngue para surdos pode ser definida como uma oposição aos discursos e às práticas hegemônicas - características da educação e da escolarização dos surdos nas últimas décadas - e como um reconhecimento político da surdez como diferença. (...) a educação bilíngue para surdos é algo mais do que o domínio, em algum nível, de duas línguas. (SKLIAR, 1999, p. 7)

Se, em outras propostas, ao surdo só é possível ser narrado pelo outro na língua do outro, nesta agora ele pode narrar-se a si mesmo dentro de sua própria língua. Além disso, é preciso sempre deixar claros os espaços que cada língua ocupa. A LIBRAS tem uma relação ideológica diversa e ocupa um espaço social 
diferente da língua oral da comunidade majoritária. Esses espaços precisam de ser defendidos e resguardados para que se garanta a cidadania.

Numa escola bilíngue, por fim, a LIBRAS e o Português devem ser situados em suas diferenças, em suas possibilidades de integração e em suas complementaridades, e não em oposição maniqueísta. Afinal, são duas, dentre as muitas línguas que constroem sujeitos e mundos.

\section{ALGUMAS REFLEXÕES LINGUÍSTICAS PARA SE PENSAR UM ENSINO BILÍNGUE/PLURILINGUE}

Consideramos que a língua (a linguagem) é o lugar da interação humana. Dessa forma, entendemos o ensino de línguas como empreendido a partir de uma visão discursiva que inter-relaciona língua, cultura e sociedade, um ensino em que a língua é considerada enquanto espaço de constituição do mundo sociocultural (TEIXEIRA E SILVA, 2010; PEREIRA, 2002; SCHIFFRIN, 1996).

Nessa perspectiva, a língua não é concebida de forma abstrata, desvinculada do momento em que se concretiza, é produzida situadamente por um sujeito que performatiza um posicionamento determinado numa certa situação, é direcionada a outro(s) sujeito(s) também determinado(s), numa situação singular, veiculando intenções singulares também. Assumimos a língua enquanto elemento político, responsável por criar espaços de representação do eu e do outro. Assim, é preciso pensar a LIBRAS enquanto língua do surdo e sua posição frente ao Português no processo de interação com o/no mundo.

Se língua é interação, levamos então em conta que a sua aprendizagem deve se dar dentro de contextos determinados, de forma sempre negociada entre os interagentes. Assim, é a relação entre os interagentes (professor-aluno, aluno-aluno, professores/alunos e discursos de outros sujeitos) que vai construir sentidos. A aprendizagem é encarada por nós como uma construção conjunta de interlocutores num contexto determinado.

$\mathrm{Na}$ abordagem do discurso, tanto o falante como o ouvinte têm papéis ativos na elaboração da mensagem e na definição 'do que está se passando aqui e agora'. (RIBEIRO; GARCEZ, 1998, p. 8)

Se a língua só existe em contextos, é a sua contextualização que nos fornecerá as bases para a sua compreensão e o seu uso, fim fundamental do ensino-aprendizagem de línguas.

Com essa perspectiva, o trabalho pedagógico é fundamentalmente o de criar oportunidades para a construção conjunta do conhecimento, uma vez que o foco está na interação, na intenção de junto com o outro construir um saber. 
No trabalho com os surdos, os focos de atenção relativos à língua oral são sobretudo dois: a leitura e a escrita. Assim, o ensino da língua terá uma perspectiva diversa, pois estaremos trabalhando o Português como língua instrumental. Enfatizamos, aqui, que o treinamento das habilidades de leitura de lábio ou de fala podem ter seus espaços fora da sala de aula. Entretanto, é na língua dos alunos que eles afinal devem aprender e apreender o mundo.

$\mathrm{Na}$ língua oralizada, as várias competências/habilidades (falar, ouvir, ler escrever - para citar as básicas) constituem (e são constituídas por) contextos sociais de interação diferentes. Então, no sentido de criar condições para o estudante desenvolver todas e cada uma, é preciso que o docente tenha clareza disso. No que se refere ao ensino de Português ao surdo, é básico, dessa forma, que se entenda como e quais situações sociais de interação se constituem pela escrita e pela leitura. Se a LIBRAS pode ser mais frequentemente a língua (o contexto) das conversações cotidianas, das interações face-a-face, o código mais utilizado no qual o surdo vai se socializar, se descobrir e se identificar, o Português - na perspectiva da escrita e da leitura - pode ocupar, complementa e integradamente, aqueles e outros espaços de interação social. Dessa forma, entendendo esta relação entre habilidades/competências, textos e o ambiente social que os orienta, o professor pode criar atividades didático-pedagógicas bem fundamentadas e contextualmente significativas para os discentes.

É fundamental que se debatam na escola esses diferentes lugares políticos e de poder que cada língua tem no sentido de que a comunidade surda se posicione social, cultural e politicamente. Assim como acontece com outras comunidades, com o "domínio" da língua oralizada, ela passa a ser também constituidora e constituinte dos sujeitos surdos.

\section{CONSIDERAÇÕES FINAIS}

A breve discussão histórico-política a que demos início aqui, além de instigante, posto que traduz e acompanha as mudanças da episteme desses últimos tempos, aponta necessariamente para outras abordagens de ensino em gestação e já em prática.

Queremos sublinhar que estas reflexões sobre ensino de línguas podem ser associadas também a alunos ouvintes. A Língua Portuguesa chamada de padrão (um construto imaginário, quase exclusivo de ensino em escolas conservadoras) e a Língua Portuguesa dos alunos ouvintes são também línguas diferentes, são também uma língua segunda e materna respectivamente. Dessa forma, também neste contexto, parece adequado pensar em um ensino bilíngue. 
Um trabalho pedagógico, nesta perspectiva que vimos apontando, traz nele mesmo uma projeção na qual a Língua Portuguesa da escola, ao ser trabalhada sob um ponto de vista sociolinguístico e político, pode vir a tornar-se um traço cultural constituidor desses alunos, e aqui incluo os surdos e os ouvintes.

Para finalizar, a partir deste ponto, ampliamos a discussão, considerando uma educação que assuma, mais concretamente, não uma bilingualidade, mas o plurilinguismo que encontramos em toda e qualquer sala de aula.

\section{REFERÊNCIAS BIBLIOGRÁFICAS}

BERNSTEIN, Basil. Langage et classes sociales: codes socio-linguistiques et contrôle social. Paris: Les Editions de Minuit, 1975.

FERNANDES, Eulália. O som: este ilustre desconhecido. In: SKLIAR, Carlos (org.). Atualidade da educação bilíngue para surdos, v. 2. Porto Alegre: Mediação, 1999.

FERNANDES, Eulália. Problemas linguísticos e cognitivos do surdo. Rio de Janeiro: Agir, 1990.

KLEIMAN, Ângela. A construção de identidades em sala de aula: um enfoque interacional. In: Lingua(gem) e identidade. Campinas: Mercado das letras, 1998, p. 267-302.

LABORIT, Emmanuelle. O vôo da gaivota. São Paulo: Best Selller, Círculo do Livro, 1994. SOARES, Magda B. Linguagem e escola: uma perspectiva social. São Paulo: Ática, 1986. MOITA LOPES, Luiz Paulo. Oficina de Linguística aplicada: a natureza social e educacional dos processos de ensino/aprendizagem de línguas. Campinas: Mercado de Letras, 1996.

PEREIRA, Maria das Graças Dias. Introdução. In: Interação e discurso: estudos na perspectiva da Sociolinguística Interacional/áreas de interface. Rio de Janeiro: Editora Trarepa, 2002, p. 7-25.

SCHIFFRIN, Deborah. Interactional Sociolinguistics. In: MACKAY, Sandra Lee; HORNBERGER, Nancy H. (eds.). Sociolinguistics and Language Teaching. Cambridge: Cambridge University Press, 1996, p. 307-328.

QUADROS, Ronice Müller. Educação de surdos: aquisição da linguagem. Porto Alegre: Artes médicas, 1997.

RIBEIRO, Branca Telles; GARCEZ, Pedro M. (org.). Sociolinguística interacional. Porto Alegre: AGE Editora, 1998.

SKLIAR, Carlos. A surdez: um olhar sobre as diferenças. Porto Alegre: Editora Mediação, 1998.

Apresentação: a localização política da educação bilíngue para surdos In: SKLIAR, Carlos (org.). Atualidade da educação bilíngue para surdos, v. 1. Porto Alegre: Mediação, 1999. 
SOUZA, Regina Maria. Que palavra que te falta? São Paulo: Martins Fontes, 1998.

SVARTHOLM, Kristina. Aquisição de segunda língua por surdos. Revista Espaço, p. 38-45, junho 1998.

TEIXEIRA E SILVA, Roberval. Português como segunda língua: contribuições para a implantação de um programa de ensino bilíngue para surdos. 2004. Tese (Doutorado em Linguística) - Programa de Pós-Graduação em Letras, Pontifícia Universidade Católica do Rio de Janeiro, Rio de Janeiro, 2004.

. A aula de língua não materna sob uma perspectiva sociointeracional. In: LIMA-HERNANDES, Maria Célia; CHULATA, Kátia de Abreu (org.). Língua Portuguesa em foco: ensino-aprendizagem, pesquisa e tradução. Salento, ed. Lecce: Pensa Multimedia Editores, 2010, p. 163-175.

. Novas territorialidades construídas em Língua Portuguesa no espaço de Macau. Platô: Revista do Instituto Internacional de Língua Portuguesa, v. 1, p. 88-100, 2012.

. Representações de países e regiões de Língua Portuguesa em materiais didáticos usados em Macau para o ensino de Português como língua não Materna. In: ROCHA, Cláudia et al. (org.). Políticas linguísticas, ensino de línguas e formação docente: desafios em tempos de globalização e internacionalização. Campinas, SP: Pontes Editora, 2015, v. 11 , p. 105-128. 